\title{
An Antenna Like Form "Hand" of the Man on Five Bands Wlan/Wimax/Hiper LAN2/C-Band Applications
}

\author{
Moufida Bouslama1, Moubarek Traii', Ali Gharsallah', Tayeb A. Denidni2 \\ ${ }^{1}$ Lab. CSEHF, Faculty of Sciences of Tunis, Tunis EL Manar University, Tunisia \\ ${ }^{2}$ Institute National of Scientific Research INRS, Energy, Materials and Telecommunications EMT, University of \\ Quebec, Montreal, Canada \\ Email: el.mof@hotmail.fr, Traii.moncef@yahoo.fr, ali.gharsallah@fst.rnu.tn, denidni@emt.inrs.ca
}

Received 25 August 2014; revised 21 September 2014; accepted 15 October 2014

Academic Editor: Vishnu Srivastava, CSIR-CEERI, India

Copyright (C) 2014 by authors and Scientific Research Publishing Inc.

This work is licensed under the Creative Commons Attribution International License (CC BY).

http://creativecommons.org/licenses/by/4.0/

c) (i) Open Access

\section{Abstract}

In this paper, a new form of printed antenna for a five-band C-band applications is presented. The proposed antenna consists of six simple rectangles, whose geometry resembles all the "hand" of man. By varying the geometries and dimensions of these six rectangles, five different resonance modes can be effectively created for five distinct frequency bands, respectively. The overall dimension of the proposed antenna can reach $45 \times 50 \times 2.54 \mathrm{~mm}^{3}$. The simulated results show that the presented antenna is adapted to $4.6 / 5.24 / 5.6 / 6.7 / 7.3 \mathrm{GHz}$ five bands which are applied to C-band.

\section{Keywords}

Patch Antenna, A Five-Band, WIMAX, WLAN, Hiper LAN2, C-Band

\section{Introduction}

In the wireless communication system, a wide range of development of technology are present today. With this advanced development, it is necessary to change a patch antenna which operates in a single frequency band, to a single antenna operating in multiple frequency bands. A multiband antenna is very interesting because it is a profitable solution for the communication system [1] [2]. Recently, many researchers have focused on the realization of different types of antennas in multi-band, such as [3] [4]. Many types of antennas have been pro-

How to cite this paper: Bouslama, M., Traii, M., Gharsallah, A. and Denidni, T.A. (2014) An Antenna Like Form "Hand" of the Man on Five Bands Wlan/Wimax/Hiper LAN2/C-Band Applications. Journal of Electromagnetic Analysis and Applications, 6, 391-396. http://dx.doi.org/10.4236/jemaa.2014.613040 
posed to realize multi-band applications. For example, a new shape of antenna was presented for mobile applications [5]. In [6], An antenna is composed of three simple circular arc-shaped strips, which resembles to the geometry proposed "ear" type to create a triple bands functioning for WIMAX/WLAN applications. In spite of antennas have many advantages, there are still some performances to improve. In [3], [4] and [6], these multi-band antennas are limited to three or two bands work. For example, in [7] a reconfigurable antenna with two frequency bands is studied which limit the working modes of communication systems. Moreover, the shape and geometry of the antenna are acting directly on the design and the cost.

In this paper, a five-band antenna WLAN/WiMAX/HiperLAN2 C-band applications is proposed. The antenna is composed of five rectangles with different dimensions and geometries which looks like a "hand" of man. The overall dimensions of the proposed antenna can achieve only $40 \times 50 \times 2.54 \mathrm{~mm}^{3}$. The simulations show that the antenna can effectively cover five separated bandwidths (4.59 - 4.7 GHz), (5.19 - 5.3 GHz), (5.58 - 5.68 GHz), (6.69 - 6.79 GHz) and (7.23 - 7.38 GHz), that satisfy the requirements of the C-band application. In addition, the antenna is well adapted to five bands with a good result in satisfactory gain in five frequency bands work.

In Part 2, we will present the quintuple-band compact antenna with a comparison of the simulation results of the simple patch antenna. Finally, we will provide the conclusion in Part 3.

\section{Antenna Design and Simulation}

Figure 1 shows the geometry of the quintuple-band which is constituted of five bands shaped rectangles that corresponds to the human fingers for WLAN/WiMAX/HiperLAN2/C-band. The antenna is adapted to $50 \Omega$, the patch "hand" is printed on top of the substrate with the dielectric constant equal to 3 and a thickness h equal to $2.54 \mathrm{~mm}$, and the ground plane is printed on the other side of the dielectric substrate. The overall size of the proposed antenna is $50 \times 45 \times 2.54 \mathrm{~mm}^{3}$.

CST Microwave Studio was used to obtain the results of the return loss of the antenna shown in Figure 1 [8]. For brevity, the basic geometry of the single antenna is not presented in this document.The physical dimensions of the antenna patch are done by the following formulae [9].

$$
W=\frac{\lambda_{0}}{2} \sqrt{\frac{2}{1+\varepsilon_{r}}}, \lambda_{0}=\frac{c}{f}
$$

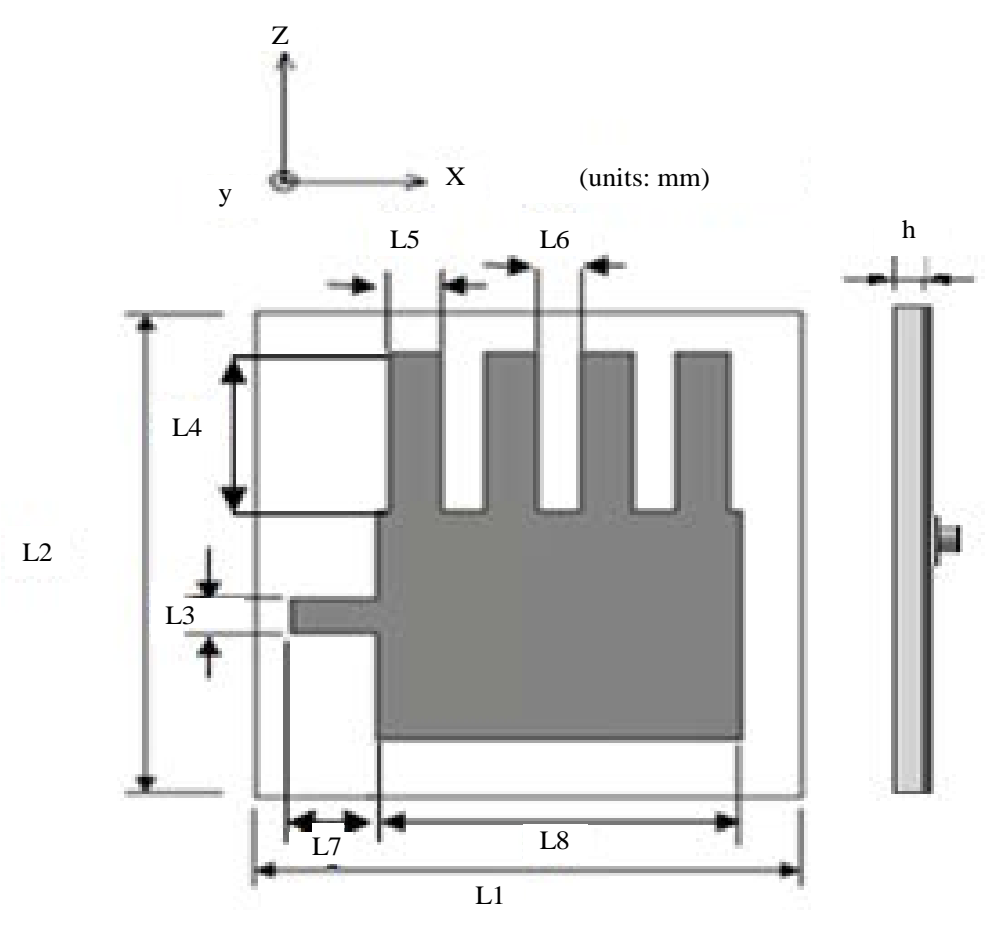

Figure 1. Geometry of the proposed antenna. 
where $W$ is the optimal width of the patch.

$$
\begin{gathered}
\lambda_{e}=\frac{c}{f \sqrt{\varepsilon_{e}}} \\
\varepsilon_{e}=\frac{\varepsilon_{r}+1}{2}+\frac{\varepsilon_{r}-1}{2}\left(1+\frac{12 h}{w}\right)^{-\frac{1}{2}}
\end{gathered}
$$

The length $L_{e}$ is determined by:

$$
L_{e}=\frac{\lambda_{e}}{2}
$$

where $L$ is the length, $W$ is the width and $C$ the speed of light. $f$ is the frequency of the proposed antenna, $\lambda_{0}$ the wavelength, $\varepsilon_{e}$ is effective permittivity and $\varepsilon_{e}$ is relative permitivity of substrate.

In Figure 2, the simulation results of planar monopole antenna and antenna in the form of the "hand" of man are combined with a good adaptation almost to the desired band. According to the results of Figure 2, we can observe that the proposed antenna can effectively cover five separate bands (4.59 - 4.7 GHz), (5.19 - 5.3 GHz), (5.58 - $5.68 \mathrm{GHz}),(6.69-6.79 \mathrm{GHz})$ and $(7.23-7.38 \mathrm{GHz})$ who can satisfy all WLAN, Wimax HiperLAN2 bands for C-band applications.

However, the basic antenna covers only two separate bands $(5.97-6.1 \mathrm{GHz})$ and $(6.8-7.1 \mathrm{GHz})$ witch limit the areas of application of the latter.

The simulated input impedance of reference antenna patch basique and the proposed antenna are shown in Figure 3. From the results, we can see the antenna is well adapted to the five bands frequency 4.6/5.24/5.6/6.7/ 7.3 GHz. However, the basic antenna is adapted for 6 and $7 \mathrm{GHz}$.

According to the mechanism of radiation of the proposed antenna, we must have quintuple-bands for which the antenna is adapted. However, when we change some key elements we can have more freedom to control the radiation performance of the antenna. In this case, the overall dimensions of the antenna "hand" (i.e. L4, L5 and L6) are the most important parameters that affect all of the radiation characteristics of the antenna. Obviously, this is because they are the main parameters controlling the transmission of the new proposed antenna shape.

Figure 4 shows the effect of these parameters in the control of the return loss. From these curves, we can observe that the level of the return loss is adapted at $4.6 \mathrm{GHz}$, in the case of the first band is strongly controlled by L4. On the other hand, Dimensions L4, L5 and L6 largely control the return loss of 5.24 and $5.6 \mathrm{GHz}$. Second, for the remaining two frequencies 6.7 and $7.3 \mathrm{GHz}$, we perceive that they are controlled by L4 and L6.

Therefore, by adjusting these parameters, an antenna shaped like a "hand" of the man who radiated in five selected bands can be achieved. Furthermore, a parametric study obtained for these dimensions in terms of the return loss is shown in Figure 5. As can be seen, the relative permittivity has a substantial effect on the radiation of the antenna for the five bands.

Figure 6 illustrates the realised gain of the proposed antenna. Average gain are about 6.95, 6.14, 6.9, 6.21 and $5.76 \mathrm{dBi}$ for 4.9, 5.24, 5.6, 6.7 and $7.3 \mathrm{GHz}$ repectiverly. So, we can see that the antenna can provide stable gains in the five frequency bands of work. Radiation characteristics above show that this antenna is a good antenna for

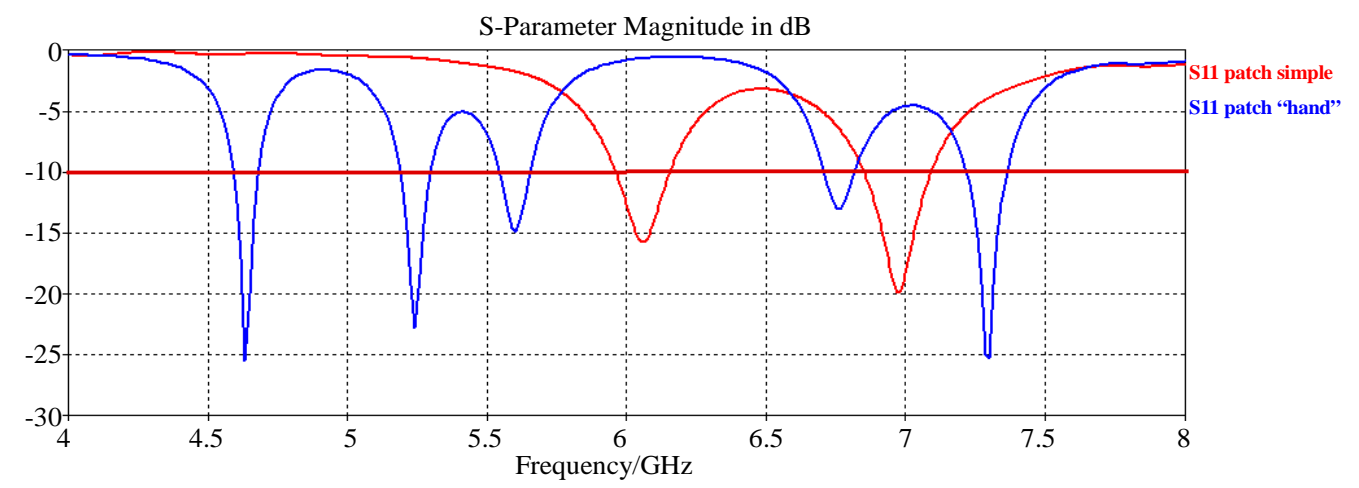

Figure 2. Simulated return loss of the reference antenna (red) and the antenna proposed (blue). 


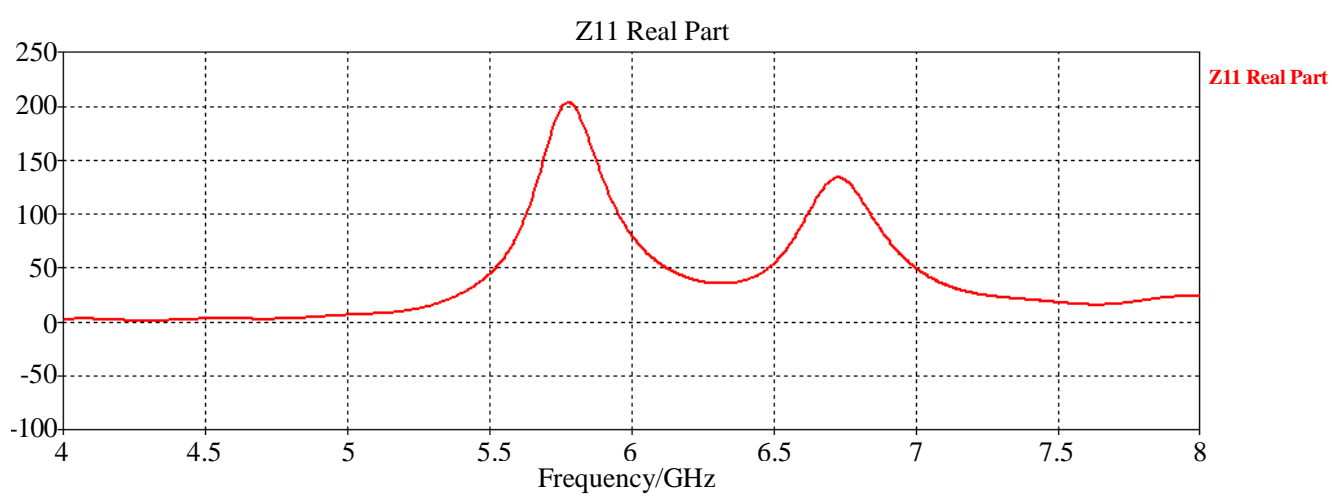

(a)

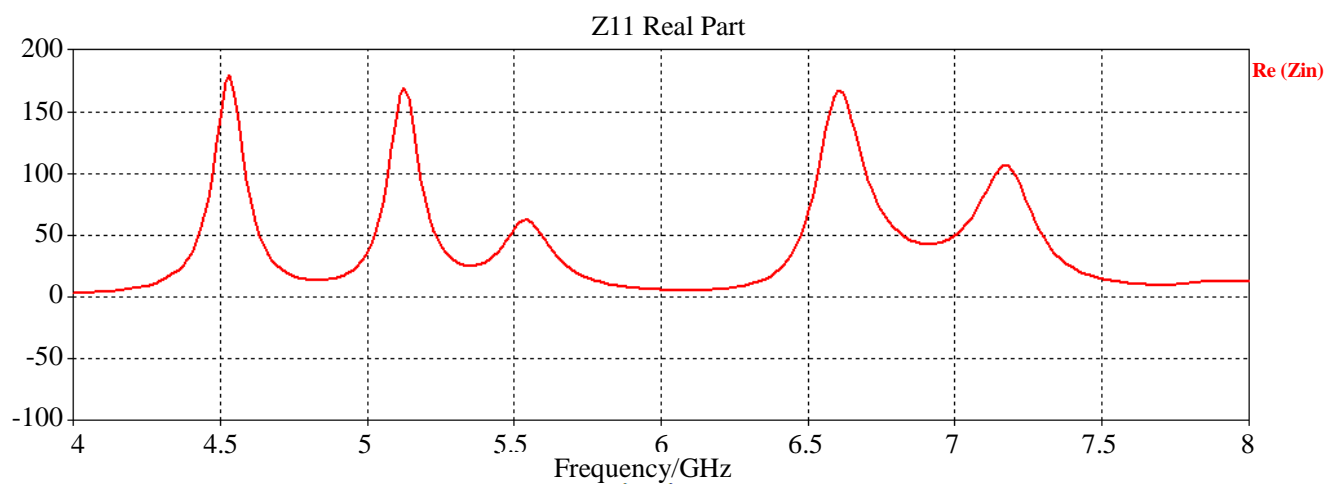

(b)

Figure 3. Simulated input impedance (real part) of (a) the reference antenna; (b) the proposed antenna.

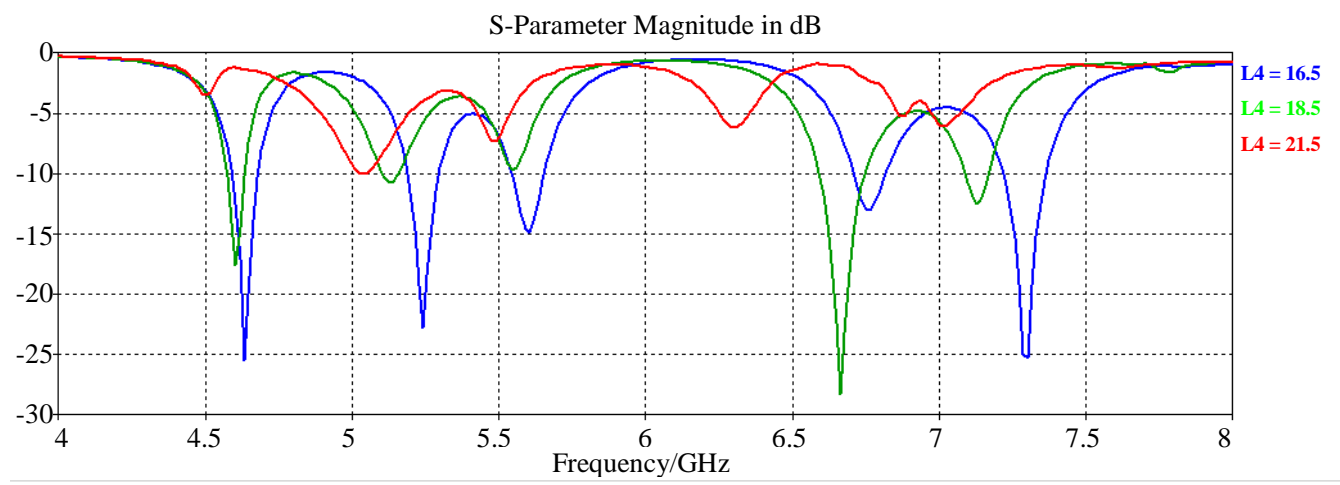

(a)

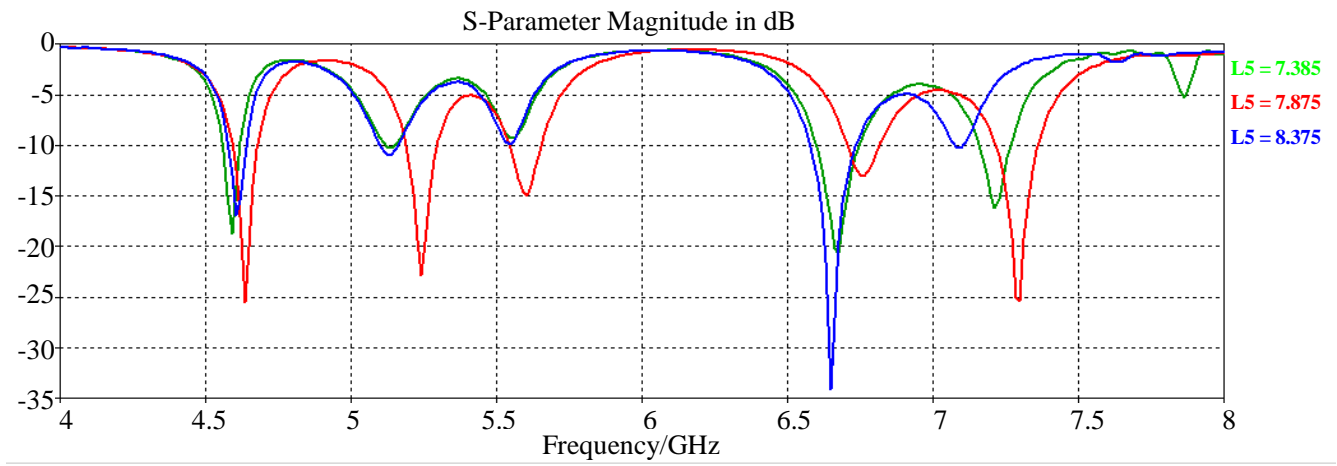

(b) 


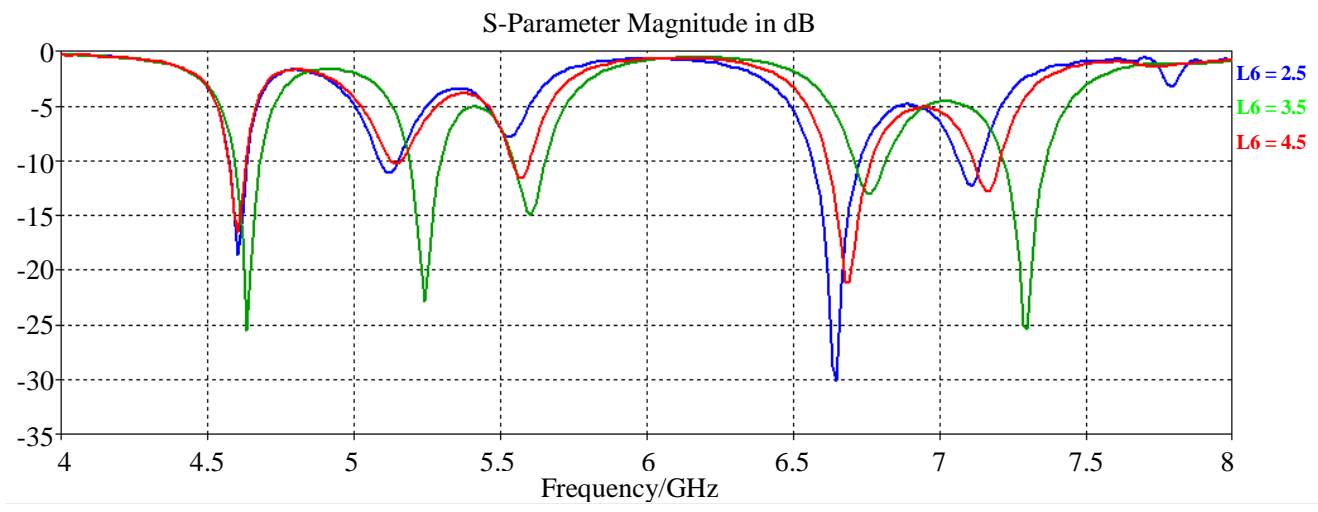

(c)

Figure 4. Parametric studies for the return loss of the antenna proposed carried out for different values of: (a) L4; (b) L5; (c) L6. The other antenna dimensions are listed in Table 1.

Table 1. Final dimensions of the simulated prototypes (MILLIMITERS).

\begin{tabular}{lccccccccc}
\hline \multirow{2}{*}{ Parameters } & L1 & L2 & L3 & L4 & L5 & L6 & L7 & L8 \\
\cline { 2 - 10 } & 45 & 50 & 2.5 & 16.5 & 4 & 3.5 & 8 & 30 \\
\hline
\end{tabular}

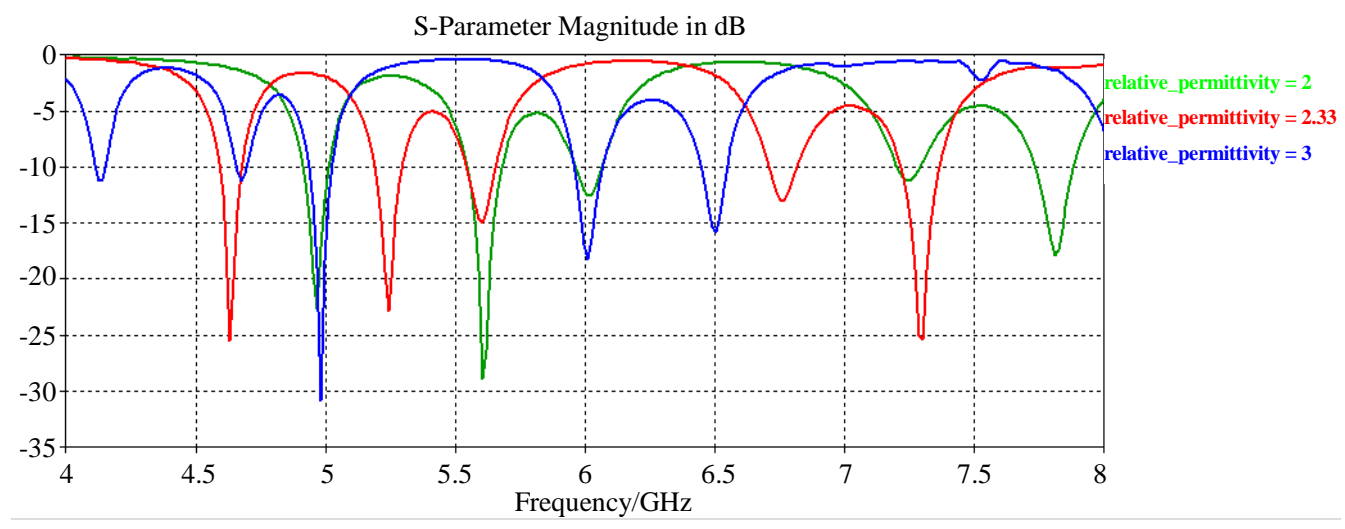

Figure 5. Parametric studies for the return loss of the antenna proposed carried of relative permittivity.

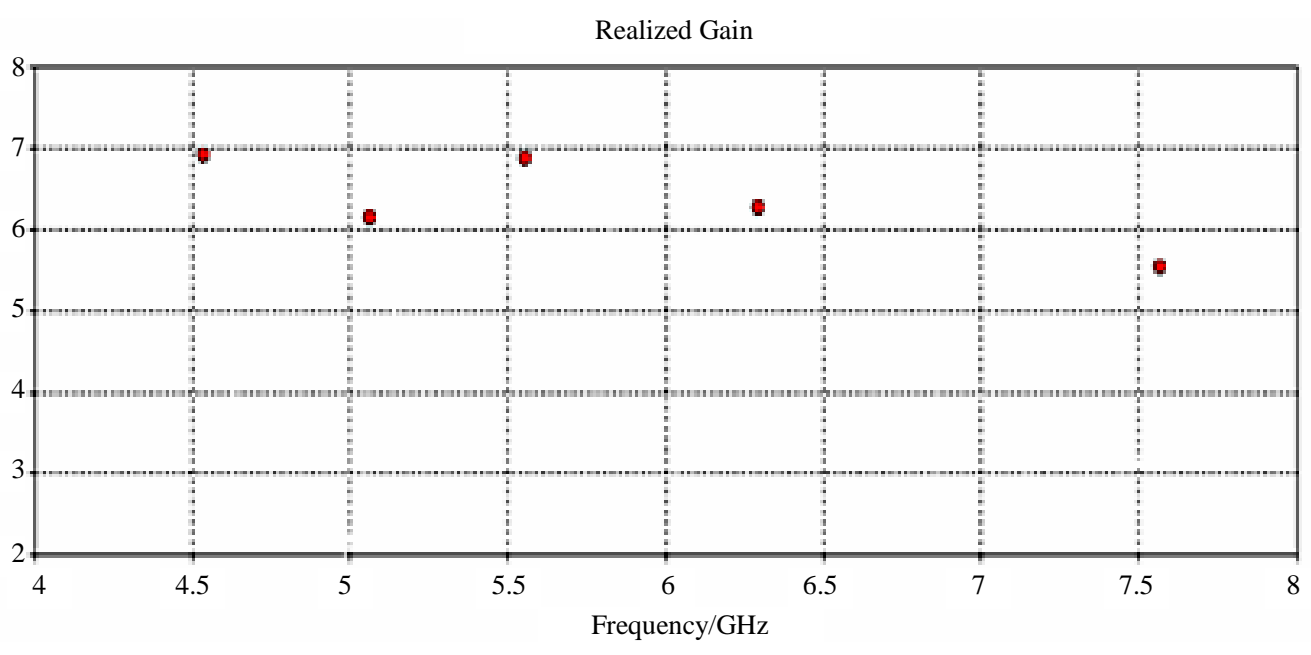

Figure 6. Simulated realised gain of the antenna. 
the quintuple band for WLAN and WiMAX and HiperLAN2 and C-band applications in the design in the design of integrated communication terminal system.

\section{Conclusion}

In this paper, hand geometrical structures with interest transformation properties have been studied for multiband wireless communications antenna applications. A new geometry printed antenna quintuple-band was developed. By optimizing the five bands in the shape of human "hand", five bands can be efficiently obtained for WLAN/WiMAX/Hiper LAN2/C-band applications, which are verified by simulated results. This antenna five bands gives good electromagnetic properties, they could be used in wireless communication systems.

\section{Acknowledgements}

The Authors acknowledge the support of the University of Quebec, INRS-EMT.

\section{References}

[1] Chaimool, S. and Chung, K.L. (2008) CPW-Fed Mirrored-L Monopole Antenna with Distinct Triple Bands for WiFi and WiMAX Applications. IET. Electron. Lett, 45, 928-929. http://dx.doi.org/10.1049/el.2009.1390

[2] Liou, C.-Y., Wu, M.-S., Yeh, J.-C., Chueh, Y.-Z. and Mao, S.-G. (2009) A Novel Triple-Band Microstrip Branch-Line Coupler with Arbitrary Operating Frequencies. IEEE Antennas and Wireless Propagation Letters, 9, 683-685.

[3] Wu, J.W., Hsiao, H.M., Luu, J.H. and Chang, S.H. (2004) Dual Broadband Design of Rectangular Slot Antenna for 2.4 and 5 GHz Wireless Communication. IET. Electron. Lett, 40, 1461-1464. http://dx.doi.org/10.1049/el:20046873

[4] Thomas, K.G. and Sreenivasan, M. (2010) Compact CPW-Fed Dual-Band Antenna. IET. Electron. Lett, 46, $13-14$. http://dx.doi.org/10.1049/el.2010.1729

[5] Naser Moghadasi, M., Sadeghzadeh, R.A., Fakher, M., Aribi, T., Sedghi, T. and Virdee, B.S. (2013) Miniature HookShaped Multiband Antenna for Mobile Applications. IEEE Antennas and Wireless Propagation Letters, 11, 1096-1099. http://dx.doi.org/10.1109/LAWP.2012.2214199

[6] Zhai, H.Q., Ma, Z.H., Han, Y. and Liang, C.H. (2013) A Compact Printed Antenna for Triple-Band WLAN/WiMAX Applications. IEEE Antennas and Wireless Propagation Letters, 12, 65-68. http://dx.doi.org/10.1109/LAWP.2013.2238881

[7] Chen, G., Yang, X.-L. and Wang, Y. (2012) Dual-Band Frequency-Reconfigurable Folded Slot Antenna for Wireless Communications. IEEE Antennas and Wireless Propagation Letters, 11, 1386-1389. http://dx.doi.org/10.1109/LAWP.2012.2227293

[8] CST Microwave Studio Simulator, 2011.

[9] Resley, L.M. and Song, H.H. (2013) Multi-Band Rectangular Patch End-Fire Antenna Array. Journal of Electromagnetic Analysis and Applications, 5, 63-66. http://dx.doi.org/10.4236/jemaa.2013.52010 